\title{
Cambios histórico-jurídicos en los Derechos Humanos para el Ejército Nacional en la Constitución colombiana de 1991. Una revisión desde la Escuela de los Annales ${ }^{1}$
}

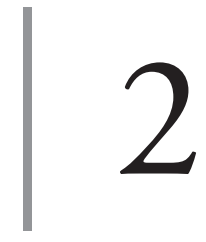

https://doi.org/10.21830/9789585287884.02

\author{
Laura Janneth Delgado Nieto \\ Escuela Militar de Cadetes "General José María Córdova”
}

\section{Resumen}

El Ejército colombiano se ha transformado militar y doctrinalmente respecto a la definición y aplicación de tácticas de acuerdo con los cambios nacionales e internacionales, así como con los fundamentos legales amparados por el legislador de cada época. Este texto hace una revisión textual de los cambios históricos-jurídicos de las Constituciones del Estado para describir cómo se han aplicado los Derechos Humanos en la institución castrense, especialmente en la carta magna que se promulgó en el año de 1991. Los resultados sugieren que los cambios que propuso esta Constitución fueron aplicados de acuerdo con los lineamientos internacionales y nacionales en beneficio de la consecución de la paz estable y duradera.

Palabras clave: Constitución de 1991; Derechos Humanos; Escuela de los Annales; Ejército de Colombia.

\section{Introducción}

La creación y modernización de un Estado es un proceso fundamentado en la guerra, puesto que

1 Este capítulo presenta los resultados del proyecto de investigación "La legitimidad de las Fuerzas Militares en la geopolítica nacional e internacional de Colombia", del grupo de investigación de Ciencias Militares de la Escuela Militar de Cadetes "General José María Córdova", categorizado en B por Minciencias y con código de registro COL0082556. Los puntos de vista pertenecen a la autora y no reflejan necesariamente los de las instituciones participantes.

2 Internacionalista y abogada de la Universidad Militar Nueva Granada. Magíster en Relaciones y Negocios Internacionales y en Historia Militar. Especialista en Docencia Universitaria de la misma casa de estudios. Profesora de la Facultad de Relaciones Internacionales de la Escuela Militar de Cadetes "General José María Córdova”, Bogotá, D. C., Colombia, y de la Facultad de Ciencias Jurídicas y Políticas de la Universidad de San Buenaventura, Bogotá, D. C., Colombia. ORCID: https://orcid.org/0000-0003-4439-1747. Contacto: laura. delgado@esmic.edu.co 
los esfuerzos por subordinar a los vecinos y luchar contra rivales más distantes crean estructuras estatales no solo de ejércitos sino también de personal civil que reúne los medios para sostener ejércitos y que organizan el control diario del gobernante sobre el resto de la población civil. (Tilly, 1992, p. 45)

Sin embargo, una nación, tanto el concepto como la entidad administrativa, es "un fenómeno de constante evolución. Ha variado desde formas organizativas simples, hasta dimensiones más complejas" (Palomo, 2011).

Todos estos cambios se condensan en documentos conocidos como Constituciones, las cuales desde el punto de vista jurídico han sido definidas como un pacto entre el soberano/gobernante y el pueblo, donde se determinan los principios básicos del gobierno y de la manera de legislación de un país, o también pueden ser entendidas como una ley fundamental que establece la organización básica del derecho público (Lassalle \& Roces, 1994).

En el caso de Colombia, las cartas constitucionales nacieron en un proceso revolucionario no pacífico (Sosa, 2006). La primera Constitución se proclamó entre 1810 y 1811. En 1810 se publicó la Constitución del Socorro, y en 1811 se erigió la Constitución de las Provincias Unidas de la Nueva Granada bajo una forma de organización federal que se había acogido en el territorio. Si bien hay un debate histórico entre cuál de estos dos documentos fue la primera carta magna, la balanza parece inclinarse hacia la promulgada en 1811 (Piedrahíta, 1992). A partir de este momento y hasta 1821 se proclamaron once Constituciones más, como lo muestra la tabla 1 .

Tabla 1. Línea de tiempo de las Constituciones

\begin{tabular}{|c|c|c|}
\hline \multicolumn{2}{|c|}{ Fecha de expedición } & Constitución \\
\hline \multirow{3}{*}{1811} & 4 de abril & Primera Constitución de Cundinamarca \\
\hline & 27 de noviembre & $\begin{array}{l}\text { Acta de Federación de las Provincias Unidas de Nueva } \\
\text { Granada }\end{array}$ \\
\hline & 9 de diciembre & Constitución de Tunja \\
\hline \multirow{3}{*}{1812} & 21 de marzo & Primera Constitución del Estado de Antioquia \\
\hline & 15 de junio & Constitución de Cartagena \\
\hline & 18 de julio & Segunda Constitución de Cartagena \\
\hline \multirow{2}{*}{1814} & 17 de julio & Constitución de Popayán \\
\hline & 23 de septiembre & Reforma del Acta Federal de las Provincias Unidas \\
\hline
\end{tabular}




\begin{tabular}{lll}
\hline \multicolumn{2}{c}{ Fecha de expedición } & \multicolumn{1}{c}{ Constitución } \\
\hline \multirow{2}{*}{22 de mayo } & $\begin{array}{l}\text { Reglamento para el Gobierno Provisorio de la Provincia de } \\
\text { Pamplona }\end{array}$ \\
21 de junio & Constitución del Estado de Mariquita \\
& 10 de julio & Segunda Constitución del Estado de Antioquia \\
& 13 de julio & Plan de Reforma a la Constitución de Cundinamarca \\
& 31 de agosto & Constitución del Estado de Neiva \\
\cline { 2 - 3 } 1821 & 30 de agosto & Constitución de Cúcuta \\
\hline
\end{tabular}

Fuente: Adaptado de Cano (2012).

Desde 1821 hasta 1886 se promulgaron en el país seis documentos más: en 1830 se publicó la Constitución de la República de Colombia; en 1832 la Constitución del Estado de la Nueva Granada y otra en 1853; en 1857 la Constitución y leyes expedidas por la Asamblea Constituyente del Estado de Boyacá; en 1858 la Constitución Política para la Confederación Granadina; el 8 de mayo de 1863 se sancionó la Constitución Política de los Estados Unidos de Colombia y el 5 de agosto de 1886 la Constitución Política de la República de Colombia, la cual tuvo tres modificaciones importantes en 1908, 1936 y 1968, y estuvo vigente hasta 1991 (Melo, 2017).

En este desarrollo constitucional siempre se contó con apartes que regulaban, a partir de su promulgación, los derechos civiles, las garantías sociales y los Derechos Humanos. De hecho, en el Título III de la Carta Magna de 1886 se contempla el "ordenamiento normativo destinado a la protección y la salvaguarda de los Derechos Humanos" (Título III de la Carta Magna de 1886). A partir de 1945, con el fin de la Segunda Guerra Mundial se revalorizaron las libertades civiles y el respeto por la vida en el sistema internacional, lo cual dio una nueva prioridad a los órdenes constitucionales de las naciones. Estos cambios iniciaron en Europa y se expandieron progresivamente por el mundo, de tal manera que "los derechos fundamentales tienen un papel relevante en las sociedades y se les dota de un complejo sistema de garantías de carácter normativo, jurisdiccional e institucional" (Arias, 2011, p. 5).

Estos textos normativos imperan para todos los sectores sociales e institucionales. En el caso de los ejércitos, debido a su función y misionalidad, la regulación de los Derechos Humanos es un pilar fundamental de su accionar. Por lo tanto, este documento indaga cuáles han sido los cambios históricos-jurídicos que la 
Constitución de 1991 plantea en Derechos Humanos para el Ejército Nacional de Colombia. Con este propósito, en primer lugar, se revisan los antecedentes históricos de estos derechos para el Ejército Nacional antes de la Constitución del 1991. Posteriormente, se analizan los cambios jurídicos que las Constituciones anteriores consagraron para el Ejército Nacional y, por último, se recopila cuáles han sido los cambios históricos-jurídicos desde la Constitución de 1991.

\section{Metodología}

Teniendo en cuenta que este trabajo analiza cuáles han sido los cambios históricos y jurídicos en el desarrollo constitucional del país que han influido en el Ejército Nacional, en este trabajo se plantea una investigación con enfoque cualitativo de tipo analítico-descriptivo. Además, la revisión documental y el análisis de la información se basó en los presupuestos metodológicos de la Escuela de los Annales, propuesta que nació durante el siglo XX en Francia y que hace un abordaje amplio de los eventos para el estudio de la historia, es decir, toma en cuenta los eventos antropológicos, sociológicos, económicos, geográficos y psicológicos. Específicamente, este capítulo se inscribe en la segunda fase de desarrollo de la Escuela de los Annales, donde se establece que las investigaciones son estudios longitudinales que se centran en establecer cambios a lo largo de la historia (Ibarra, 2019).

Las fuentes revisadas se encuentran en la Biblioteca Central de las Fuerzas Militares “Tomás Rueda Vargas”, en la Academia Colombiana de Historia Militar, en la Academia Colombiana de Historia, la Real Academia de Historia de España y en las bases de datos de la plataforma oficial de la Fuerza Pública, Blackboard, así como en la Biblioteca Luis Ángel Arango, del Banco de la República. Como criterio de selección se determinó que estas fuentes debían ser documentos con información certera para que cumplieran con las condiciones académicas del caso y pudieran ser incluidas en esta pesquisa.

\section{Resultados}

\section{Época colonial}

Este periodo se refiere al tiempo después de la conquista y del llamado "descubrimiento de América por parte de España, Portugal y luego Inglaterra, a finales del siglo XV”. En la época colonial estos países no solo impusieron diferentes clases 
sociales y organizaciones políticas, sino que además realizaron diversas reformas a la economía e introdujeron cambios culturales, de tal manera que los territorios de ultramar tuvieron que reconocer principalmente a la Corona, en cabeza del rey de España, como ente dictatorial. Asimismo, se legitimó el Real Consejo de Indias como institución política, administrativa y judicial, mientras que se designó a la Casa de Contratación la función de regular las actividades comerciales.

Los cambios que realizaron los europeos cuando llegaron a imponerse en estos nuevos territorios fueron tan drásticos que generaron otras subdivisiones socioeconómicas, las cuales crearon bastantes tensiones con las etnias indígenas. Los nativos americanos fueron los primeros afectados, pues no poseían los medios de protección ni la fuerza física necesaria para contrarrestarlos, por lo que no pudieron evitar los planes de expansión y genocidio. Esta situación se presentó a pesar de que Isabel la Católica manifestó su preocupación por los derechos de los indígenas, determinó que ellos seguirían siendo los propietarios de las tierras que les pertenecían con anterioridad a la llegada de los españoles y en el año 1500 dictó un decreto prohibiendo la esclavitud (Azcona, 1992, p. 420).

De igual forma, la Ley de Indias, escrita por Fray Bartolomé de las Casas en 1521 (Martínez, 2015), tampoco tuvo el efecto que esperaba, pues

el sometimiento y la disminución de los pueblos indígenas originarios, por medio de masacres genocidas, esclavitud, conversión religiosa forzosa, desplazamiento de sus territorios, y otros, fue parte integral del proceso de conquista y colonización llevado a cabo por naciones europeas que usaron su poder militar, la religión, la cultura y el lenguaje para dominar a los grupos indígenas con el fin de extraer los ricos recursos naturales del continente. De hecho, el mismo concepto de "pueblos indígenas" es inseparable de aquellos de "imperialismo" o "colonización”. (Coates, 2004; citado por Rubaii, Líppez-De Castro \& Appe, 2019, p. 32)

Cuando los españoles se dieron cuenta de que no contaban con los resultados esperados para satisfacer las elevadas cuotas que imponía la monarquía europea, decidieron aumentar la importación de cientos de hombres y mujeres de raza negra provenientes de sus otras colonias ubicadas en África. Estos fueron traídos desde el otro lado del mundo como esclavos para continuar la usurpación y el dominio de las estructuras sociales.

Estas personas de color también ofrecían protección y respaldo a sus dueños, de manera que con el paso del tiempo empezaron a tener diferenciaciones de rango y consideraban que era un honor servir al monarca. Como afirma Marchena (1990),

en 1779, José de Gálvez —a la sazón ministro de las Indias (1776-1788) — justificó la reforma invocando el principio según el cual, para los americanos, como 
para los españoles, "la defensa de los derechos del Rey está unida a la defensa de su propiedad, sus familias, su patria y su felicidad". (p. 233)

Como parte de su trabajo, estos grupos de personas negras e indígenas recibieron capacitación de extranjeros —en gran parte provenientes de España-, quienes les enseñaban a tener una defensa básica y rudimentaria que no tenía mayor direccionamiento en temas de protección, sino que, por el contrario, sus formas de actuar eran muy cuestionadas debido a que utilizaban y manipulaban incorrectamente la pólvora en muchas situaciones. Estos hombres "seleccionados para el servicio militar eran organizados en unidades y, bajo el mando de oficiales de milicia y experimentados soldados o ex soldados regulares, se sometían a una rutina de entrenamiento militar armado a intervalos semanales" (McFarlane, 2008, p 234).

Todas estas personas reclutadas tenían una función (acompañante, escolta, protector, mensajero o esclavo, en una gran cantidad), pero ninguno contaba con instrucciones precisas sobre las libertades civiles, sino que en su formación primaba el beneficio del rey y de la Corte española, que después de un tiempo fue conformada por los hijos de los españoles. Durante este proceso, cada provincia determinó la organización del Ejército en los principales pilares y de acuerdo con la conveniencia del designado por España (tabla 2).

En la tabla 2 se puede ver que la mayoría de las personas que conformaron el nuevo Ejército de América fueron los extranjeros y sus descendientes, quienes constituyeron las bases de poder y ascendían fácilmente, pues con el paso del tiempo recibieron inmunidades para el trato con la población civil, lo cual desencadenó rebeliones en las poblaciones de Quito, Cali, Cartago y El Socorro (Lynch 2001, p. 90; citado por Chaparro, 2010, p. 63).

En este contexto social, el programa de fortalecimiento militar de esta época se basó en el Reglamento para las Milicias Disciplinadas de Infantería y Dragones del Nuevo Reyno de Granada, y Provincias agregadas a este Virreinato, elaborado en 1794. Este documento describe las situaciones vividas en batalla y las replantea como normas de comportamiento:

Desde principios de siglo en Cartagena y Panamá ya se estaban elaborando reglamentos y planes discrecionales de tropa que buscaban, entre otras cosas, codificar el haber mensual y la preparación estratégica de los puertos, así como los planes de fortificación y los asuntos de guarnición, pero estos se dictaban de forma individual para atender al funcionamiento defensivo de cada Plaza. (Marchena, 1982) 


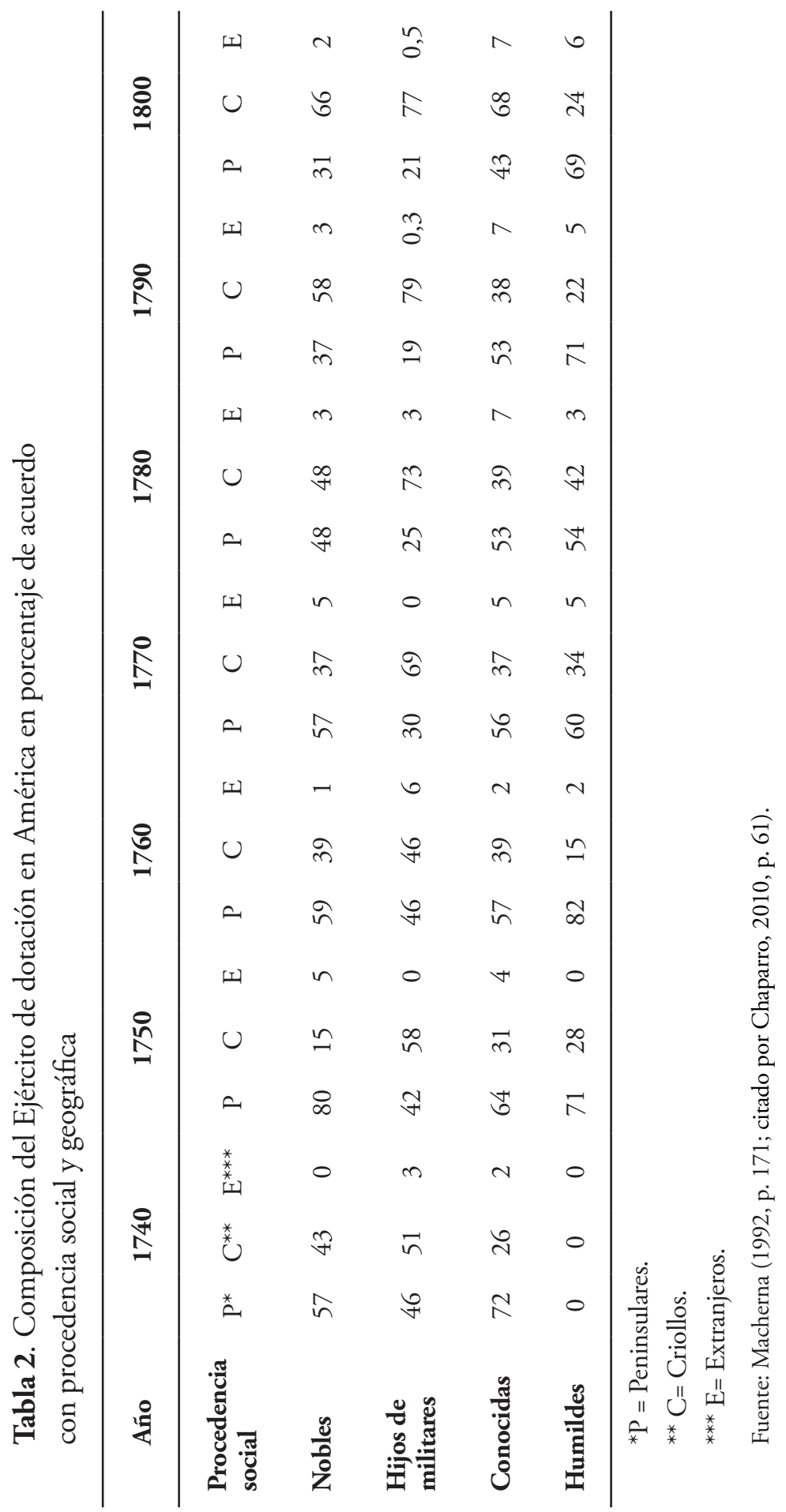


Aunque entre los habitantes de la República había civiles y personas con rangos militares, blancos, mestizos, negros, zambos e indígenas que convivían con los criollos, estos últimos contaban con una situación muy diferente, ya que al ser hijos de europeos nacidos en América, poseían los mismos derechos de los ciudadanos de Europa. Debido a su condición particular, los criollos consideraban que debían arrasar con los invasores de este territorio, luchar para conservar el poder absoluto y dirigir el destino del país. Además, que este no debía ser determinado por los indígenas ni los esclavos, aunque teóricamente afirmaran la igualdad de los hombres en la Nueva República.

Esta circunstancia determinó que la nueva sociedad no tuviera —en el discurso - una fuerte aristocracia territorial — aunque en la práctica era otra - y que se desarrollara como un país comerciante, con técnicas de pan coger, lleno de burócratas y artesanos, mientras concentraba la distribución de la riqueza en unas pocas personas. Como consecuencia se suscitaron nuevos movimientos y gestas revolucionarias que no tuvieron una política clara alrededor del respeto de los derechos del hombre - hoy conocidos como Derechos Humanos- para los habitantes de las Américas, pues los cuerpos militares de la nación solamente tenían el interés de cuidar a la alta aristocracia.

En esta época Antonio Nariño hizo la traducción clandestina de los Derechos del Hombre (Ruiz, 1929) y en agosto de 1794 en los principales lugares públicos de Santafé amanecieron fijados unos pasquines manuscritos con esta publicación. El virrey Ezpeleta inició de inmediato la investigación con base en la declaración de "Francisco Carrasco, un alcohólico jerezano de pésimos antecedentes, [quien] recuerda que ocho meses antes había visto un papel sobre las leyes de la Asamblea de Francia y acusa a Narińo de ser su autor" (Ruiz, 1929). En este contexto social hubo distintos personajes que decidieron luchar para liberarse del yugo español que los coartaba y que limitaba hasta sus pensamientos, ya que su poderío imperaba en todos los temas en general a través de las imposiciones del Virreinato.

Este proceso de lucha se decantó en el año de 1810, cuando se promulgaron varias "actas de independencia" que expresaban su deseo de levantarse contra los gobernantes espańoles localizados en las colonias y provincias del Nuevo Mundo (virreyes, gobernadores, corregidores), mas no independizarse del Estado español, sino manifestar que estos gobernantes eran ilegítimos porque en 1808 el ejército de Napoleón Bonaparte había invadido a España y depuso a su rey, Fernando VII.

Juramos por el Dios que existe en el Cielo, cuya imagen está presente y cuyas sagradas y adorables máximas contiene este libro, cumplir religiosamente la Constitución y voluntad del pueblo expresada en esta acta, acerca de la forma del Gobierno provisional que ha instalado; derramar hasta la última gota de nuestra sangre por defender nuestra sagrada religión C. A. R. nuestro amado Monarca Don Fernando 
VII y la libertad de la Patria; conservar la libertad e independencia de este Reino en los términos acordados; trabajar con infatigable celo para formar la Constitución bajo los puntos acordados, y en una palabra, cuanto conduzca a la felicidad de la Patria. (Acta de Independencia, Acta del Cabildo Extraordinario de Santa Fe, 1810)

El siglo XVIII marcó la decadencia de los imperios y claramente la pérdida de la hegemonía que tenía España en Europa debido al debilitamiento de su sistema marítimo. Además, el aumento de la población que se había asentado en América generó diferentes intereses que forzaron la creación de un libre tránsito de comercio ilegal que ya no podía ser controlado por la Corona. Como consecuencia, en 1778 se proclamó el libre comercio entre los puertos de América y los de España, lo cual generó una descapitalización visible en la balanza de pagos que lo único que trajo fue ruina para los comerciantes americanos, quienes no sabían perder y reaccionaron con insurrecciones y situaciones de desapego que se marcarán con el paso de los años, como se describe posteriormente.

\section{Promulgación de los Derechos Humanos en Colombia}

La historia de la promulgación de los Derechos Humanos en Colombia comienza en Francia en 1789 con la Declaración de los Derechos del Hombre y del Ciudadano — base de las constituciones modernas—, pues fueron la fuente de inspiración para que Antonio Nariño divulgará en 1794 los Derechos del Hombre y del Ciudadano (Ruiz, 1929). No obstante, este documento fue leído y acatado a conveniencia del gobernador debido a que los poderes del monarca eran ilimitados por los fueros y estaban por encima del derecho del pueblo.

Adicionalmente, estos derechos no existían para los indígenas ni para los esclavos. En esta época solo existía la proclama de la reina Isabel y los escritos de Fray Bartolomé de las Casas, quien adaptó, junto con otros clérigos, una reglamentación de protectorado que en alguna medida también contemplaba a los negros. Los escritos promulgaban medidas de cuido y prohibían a los amos darles muerte, al tiempo que permitían otorgarles la libertad en ciertos casos y mediar en asuntos menores (Martínez, 2015).

Es importante resaltar que durante el periodo colonial se protegía los derechos individuales y personales de la clase alta, como los bienes y la honra, pero la situación era muy diferente para las personas del común, a quienes se les negaba el derecho a la vida, a sus libertades de conciencia o de religión, puesto que la enseñanza era planeada por las autoridades eclesiásticas y políticas. 
En respuesta a lo anterior, la población comenzó a gestar corrientes de cambio que decantaron en el movimiento independentista de 1810. A partir de esta fecha, los dirigentes y ejércitos del momento adoptaron el lenguaje del pensamiento más liberal, según el cual los pueblos debían ser libres y el propósito del gobierno era proteger y regular los "derechos imprescriptibles del hombre y del ciudadano" (Melo, 2017). Lamentablemente, se continuaba pensando en el protectorado de la Corona o de un ente superior extranjero que fortaleciera los cambios suscitados -que a futuro cobrarían fuerza-, lo cual trajo bastantes retrocesos a la independencia real de España.

\section{Constituciones de Colombia entre 1819 y 1886}

Con la promulgación de la independencia definitiva del Virreinato de Nueva Granada en 1819, se elaboraron diferentes constituciones — llamadas provincialesque tenían grandes diferencias en el trato y manejo de las actividades que servían al rey. Por lo tanto, se habían promulgado mil y un decretos que tenían múltiples disposiciones que eran de carácter obligatorio, pero que perdieron vigencia luego de las insurrecciones de los nacionales y algunos extranjeros que derrocaron el yugo español. Todas estas Constituciones estaban muy ligadas al mando militar, debido a que su lineamiento y legitimidad estaban constituidas por la reglamentación de los políticos, que versa en la protección de la soberanía y del pueblo.

Sin embargo, a pesar del espíritu de autodeterminación que inspiraba estas Constituciones, aún seguía presentela organización político-económica que los españoles diseñaron. Como ejemplo de esta afirmación se puede citar la Constitución del Estado de Cundinamarca, la de Tunja y la de Antioquia, todas promulgadas en el año de 1811, que versaban sobre la organización jurídico-religiosa y política, y que en sus dos primeros capítulos regulan los derechos y deberes del hombre en sociedad. Aun así, estos textos también evidencian que se comenzaba a considerar la preexistencia de las normas, que enmarca, junto con el principio de la legalidad, una característica fundamental de un estado de derecho. Como lo manifiesta Karla Pérez, "la vinculación del principio de legalidad a todos los poderes del Estado se da en diferentes niveles. Así, tiene una presencia mucho más fuerte en el Ejecutivo que en el Jurisdiccional y, finalmente, una apenas deducible influencia en el legislativo" (Pérez, 2005).

En este punto es importante aclarar que debe haber una especificación tácita de una reglamentación escrita para que al ser distribuida y, en muy pocos casos, socializada, se enmarque como principio legal lo que se plasma allí, de manera que la población tenga tranquilidad sobre los preceptos legales que supuestamente la 
cobijan. Pero que claramente desconfían, lo cual da paso a más textos normativos constitucionales.

Posteriormente, en 1812 se escribieron las Constituciones de la República de Cundinamarca y la del Estado de Cartagena, que se "fundamenta en la creación de la Constitución en el derecho de los pueblos para que se diera una forma de gobierno que asegure su felicidad expresa del pacto social [...] y consiente en hacerse parte de un gran todo político" (Preámbulo Constitución del Estado de Cartagena de Indias, 1812). Este texto va en la misma línea con la anterior carta magna de Tunja, pues seńala los derechos del hombre en sociedad y los deberes del ciudadano, que también incorporaron la del Estado de Mariquita, la provisional de la Provincia de Antioquia y la de la Provincia de Neiva, en 1815.

En 1820, Simón Bolívar promulgó un decreto que ordenaba la devolución a los indígenas, como propietarios legítimos, de todas las tierras que formaban los resguardos según los títulos — cualquiera que estos fueran- que alegaran para poseerla los actuales tenedores (Decreto de 5 de julio de 1820). Este mandato le permitió tener un mayor acompañamiento en la Batalla de Carabobo, el 24 de junio de 1821, que otorgó la independencia de Venezuela y la liberación de Caracas, Cartagena, Popayán y Santa Marta. Con esta victoria, el 18 de julio se retomaron en Cúcuta las reuniones para redactar un texto de carácter nacional que incluyera las regiones que ya estaban emancipadas.

Luego, el 30 de agosto de 1821, el Congreso de Cúcuta escribió la Constitución de Cúcuta, la cual dio vida legal a la República de la Gran Colombia, formada por los territorios que actualmente corresponden a Colombia, Venezuela, Ecuador y Panamá. Esta carta magna estuvo vigente durante toda la Gran Colombia hasta su disolución en 1830, año en el que también se debe resaltar la creación de la Procuraduría General de la Nación con el fin de promover las leyes civiles y militares (Procuraduría, 2020).

Estos decretos animaron a los habitantes de las Américas que participaron en las diferentes afrentas contra los españoles entre 1819 y 1825, así como las grandes hazańas del Ejército libertador neogranadino durante las campañas libertadoras. En este contexto surgió la necesidad de formar una escuela de enseñanza militar que, idealmente, fuera una copia de la que estaba en West Point en los Estados Unidos, para que en ella se formará una clase élite de oficiales. Sin embargo, no se tenía el presupuesto ni la autorización del Congreso para construirla, de modo que la conformación de tan selecto grupo de hombres capacitados en temas de estrategia de guerra moderna y construcción de fortificaciones solo quedó en propuestas (Prado, 2017, p. 322). 
Posteriormente, después de varios intentos, en 1834 el Congreso, al mando del presidente Francisco de Paula Santander, promulgó la Ley Orgánica de las Fuerzas Militares, que estableció un equilibrio entre la necesidad de formación técnica-militar y la precariedad del presupuesto nacional. Para atender las necesidades regionales, esta ley decretó que se impartieran cátedras de asignaturas castrenses en las universidades de acuerdo con la especialidad de cada localidad, que estaban divididas en $1 .^{\circ}, 2 .^{\circ}$ y $3 .^{\circ}$ distrito, que serían Bogotá, Cartagena y Popayán, respectivamente (Ley Orgánica de las Fuerzas Militares, 1834).

Seguidamente se redactó la Ley del $1 .^{\circ}$ de junio de 1847 y el Decreto del 20 de julio del mismo año, que dieron vía libre a que el 2 de enero de 1848 se abriera el Colegio Militar en Bogotá, donde se impartieron clases de ingeniería civil y militar aplicadas a las técnicas de guerra que robustecieron los mandatos militares. Asimismo, en este periodo hubo avances tangibles en la sociedad civil, como la liberación de los esclavos en 1851, que se fortaleció con la expansión gradual de las libertades políticas y de las ideologías escritas, expresadas como libertad de prensa, que junto con las garantías legales y procesales permitían a un ciudadano hacer valer su derecho frente al Estado de una manera diferencial (Tovar, 2017).

Este Colegio Militar estuvo abierto hasta el 17 de abril de 1854, cuando tuvo lugar el golpe de Estado del general José María Melo. Después de la caída de esta dictadura en diciembre del mismo año, el ambiente antimilitarista fue la causa de que se clausurara la enseñanza de temas militares fuera del ámbito castrense (Prado, 2017, p. 326).

Posteriormente, la Constitución de 1853, de corte liberal, abrió la puerta al federalismo y confirmó legalmente la eliminación de la esclavitud. Adicionalmente, otorgó el poder del sufragio a todos los hombres y promulgó la inimaginable separación entre la Iglesia y el Estado (Pombo, 1951). Cabe agregar que en esta época también tuvo lugar otro hito en el reconocimiento de los Derechos Humanos: en 1861 se abolió legalmente la pena de muerte en el territorio.

Dos años después, en 1863, los liberales radicales que ganaron la guerra civil que había iniciado en 1860 promulgaron la nueva Constitución de Rionegro, la cual decretó la libertad de pensamiento en forma oral o escrita; el derecho de gentes; la libertad para trabajar u organizar cualquier negocio; la libertad de imprenta; la libertad para viajar por el territorio, entrar o salir de él; la libertad de enseńanza; la libertad de culto; la libertad de asociación, y la libertad de poseer armas y municiones (Pérez, 1959, p. 181).

Desde entonces existieron varias reformas constitucionales hasta que se promulgó la Constitución de 1886 durante la presidencia de Rafael Reyes, para lo 
cual se estructuró una asamblea constituyente conformada por delegatarios de los nueve Estados (dos por cada Estado). Orientada principalmente por los principios ideológicos conservadores, la Constitución de 1886 — que ha tenido la vigencia más prolongada en la historia del país — renombró el territorio como República de Colombia, devolvió los poderes a la iglesia, estableció el catolicismo como religión oficial, desmontó el sistema federal e impuso una política del mando central, con lo cual unificó las Fuerzas Armadas de cada departamento y declaró un único gran Ejército Nacional.

\section{Constitución de 1991}

En 1991, el Estado, en cabeza del presidente César Gaviria Trujillo, dio paso a la última reforma constitucional vigente. Esta carta política fue promovida por el movimiento Séptima Papeleta, que pedía una nueva legislación que fuera de la mano con la protección de las instituciones de defensa de los Derechos Humanos y que creara diferentes organismos para aplicarlos debidamente.

Esta Constitución dio un amplio reconocimiento a los derechos de las poblaciones indígenas, instituyó legalmente la tutela, creó organismos como la Defensoría del Pueblo, amplió el inventario de los Derechos Humanos con varios derechos económicos y sociales (cultura, empleo, salud, vivienda, etc.) e incluso convirtió en derechos de los ciudadanos algunos de los objetivos básicos del orden constitucional, como la paz.

También es importante agregar que esta carta magna integró claramente tres generaciones de Derechos Humanos: la primera generación incluye los derechos civiles y políticos, la segunda reconoce los derechos económicos, sociales y culturales, mientras que la tercera fomenta la solidaridad entre los pueblos y las personas de todo el mundo, de tal manera que su función principal es promover relaciones pacíficas y constructivas que permitan a las sociedades afrontar los nuevos retos a los que se enfrenta la humanidad (Leiva et al., 2018).

Respecto a las Fuerzas Militares de Colombia, el artículo 217 de la Constitución Política establece que están constituidas por el Ejército Nacional, la Armada y la Fuerza Aérea. Asimismo, les asigna el objetivo de defender la soberanía, la independencia, la integridad territorial y el orden constitucional, de tal manera que las autoriza constitucional y legítimamente para cumplir su misión mediante el uso del armamento, siempre en estricto respeto y protección de los Derechos Humanos y la cabal aplicación del Derecho Internacional Humanitario. En este sentido, la esencia de estas organizaciones armadas y el fundamento de su instrucción es la disciplina en el desarrollo de la técnica militar, que está rigurosamente jerarquizada. Por esta 
razón, el cumplimiento de su misión constitucional depende del acatamiento del mando que tienen los superiores directos sobre los comandantes y subalternos, es decir, el vínculo mando-obediencia entre superiores y subordinados.

Por su parte, el artículo 67 de la Constitución Política establece que la educación militar y policial debe poseer contenidos curriculares propios, según los niveles y particularidades de cada Fuerza y en línea directa con la misión institucional y las políticas de los ministerios de Defensa y de Educación. Al respecto, cabe agregar que la Ley 30 de 1992 definió que las Fuerzas Militares deben recibir

formación y entrenamiento en valores éticos, morales, cívicos, sociales, culturales y democráticos que conduzcan, además de su profesionalización, al mantenimiento y sostenibilidad de la paz, al fortalecimiento de la proyección social de las instituciones militares y policiales y al diálogo de saberes con la sociedad. (Ley 30 de 1992)

Por lo tanto, el artículo 222 de la Constitución señala que "en las etapas de su formación, [a los miembros de estas Fuerzas] se les impartirá la enseñanza de los fundamentos de la democracia y de los Derechos Humanos". Es por ello que, para el efecto, se unificó en la Fuerza Pública un modelo pedagógico para enseñar los Derechos Humanos y el Derecho Internacional Humanitario, que permiten interiorizarlo y articularlo en la actividad profesional y misional de la institución.

Posteriormente, en el año 2007, la Política Integral de Derechos Humanos y Derecho Internacional Humanitario, expedida por el Ministerio de Defensa Nacional, definió el marco jurídico que regula las operaciones militares y los operativos policiales. Aunque sobrepasa el periodo de análisis, conviene resaltar que todo lo que se promulgó en la Constitución de 1991 no se aplicó inmediatamente debido a las diferencias políticas-económicas, que estaban siendo atacadas por el narcotráfico y las guerrillas existentes. Sin embargo, la carta política sí propició que se comenzaran a crear los estamentos y cartillas que luego entraron a fundamentar la formación de las Fuerzas Militares en Derechos Humanos y Derecho Internacional Humanitario.

Asimismo, es muy importante resaltar que el Ejército Nacional de Colombia no puede participar abiertamente en la contienda política. Así lo estableció en 1958 el presidente Alberto Lleras Camargo en su famoso discurso del Teatro Patria, donde propuso que como garantía para superar la masacre partidista durante la época de la Violencia, las Fuerzas Militares se mantuvieran al margen de la política. De esta manera, las Fuerzas Militares se transformaron en organismos "no deliberantes", sin derecho al voto ni a postularse para cargos de elección popular, medida que sesgó en algunos campos a los uniformados. 
De esta forma se manifestó el deseo de separación de las Fuerzas y la individualización de los integrantes que deseen tener representaciones públicas de algún color político, pero que igual entran a servir los preceptos definidos por ellos. Es por esta razón que las Fuerzas Militares, especialmente el Ejército Nacional, son actualmente un marco de referencia para la protección de la soberanía, así como para la salvaguarda y la máxima representación de la democracia. No obstante, no se puede subordinar a ningún precepto que esté enmarcado en la legislación vigente, donde se ve que de acuerdo con la época y su dirigente, han aplicado los Derechos Humanos vigentes.

\section{Conclusiones}

De acuerdo con la investigación sobre los cambios histórico-jurídicos de las constituciones respecto a los Derechos Humanos para el Ejército Nacional de Colombia, así como el estudio específico de la Constitución de 1991, se concluye que el mando — que en este caso sería el presidente de la República de Colombia—, en delegación con el ministro de Defensa y los grupos de trabajo de las tres Fuerzas Militares (Ejército, Armada y Fuerza Aérea), emiten las diferentes directrices para que a través de los comandantes militares se imparta la Política Integral de Derechos Humanos y Derecho Internacional Humanitario.

Lo anterior busca la integración plena de los lineamientos a la instrucción táctica y a la lógica operacional, que son la columna vertebral de este proceso. De este modo, se ejecuta la ley en todo el territorio desde el inicio, cuando los miembros de la Fuerza Pública reciben las instrucciones básicas militares, que adicionalmente se refuerzan en diferentes avances de grado y en las unidades donde son trasladados cada dos años.

En el caso especial de las diversas actividades militares, el estudio muestra cómo por medio de la adaptación a las normas internacionales y nacionales se han construido diversos manuales de operaciones. Entre estos, se destaca el primer Manual de Derecho Operacional, que expidió el Comando General de las Fuerzas Militares y que entró en vigencia el 15 de diciembre de 2009. Este documento está dirigido a los comandantes militares hasta el nivel de unidad táctica (nivel de batallón), a los asesores jurídicos operacionales y a los operadores jurídicos, incluyendo autoridades judiciales militares y ordinarias, así como a los abogados de la defensa. En este documento se explican las herramientas jurídicas necesarias para que los miembros de las Fuerzas Militares comprendan las normas nacionales e internacionales y la doctrina operacional aplicable a la conducción de las operaciones militares. 
Adicionalmente, la revisión documental evidencia que no solo se cuenta con las lecciones aprendidas por las Fuerzas Militares para fundamentar y no volver a cometer los mismos errores, sino que también existen los diferentes informes que el personal militar debe entregar al Estado sobre las acciones realizadas, en los cuales hay un apartado especial para explicar claramente cómo se aplicó la fuerza y de qué manera se respetaron los Derechos Humanos.

Por último, se concluye que si bien Colombia ratificó las Convenciones de Ginebra en el año de 1960 y las incorporó formalmente en su ordenamiento, no fueron implementadas dentro de las instituciones militares ni citadas en los procesos judiciales (Comisión Colombiana de Juristas, 1997). Solo al finalizar los años ochenta se hizo referencia a las Convenciones y se aplicaron directamente, puesto que, en la práctica, las garantías procesales mínimas de los Convenios de Ginebra eran aplicables a quienes eran detenidos por militares o juzgados en los llamados consejos verbales de guerra.

De acuerdo con Villa (1994), "la única mención explícita al AC3 en manuales castrenses después de la ratificación de los Convenios aparece en el Manual de Campaña del Ejército, de 1988, el cual ni explica el contenido de la norma ni incluye su texto". Esto evidencia, por un lado, el interés por avanzar en el tema, pero, por el otro, muestra que no hubo un correcto direccionamiento ni se aclararon los mecanismos mediante los cuales se acatarían los Convenios. Como consecuencia, era casi imposible realizar el debido lineamiento y, por lo tanto, las técnicas utilizadas tenían otros fines según la época.

Finalmente, se vislumbra claramente que gracias a que los manuales han aplicado y fundamentado de manera correcta los Derechos Humanos y el Derecho Internacional Humanitario, ha cambiado el curso de los enfrentamientos por el respeto y la lucha de la soberanía nacional. Como resultado de este proceso se tiene la construcción de un Ejército Nacional que es, como siempre, respetuoso de sus reglamentos y que acata la norma de acuerdo con lo previsto para lograr el fin que describe el artículo 22 de la Constitución Política Nacional de Colombia, el cual establece el derecho a una paz estable y duradera.

\section{Conflicto de intereses}

La autora declara que no existe ningún potencial conflicto de interés relacionado con este capítulo.

\section{Financiación}

La autora no declara fuente de financiamiento para la realización de este capítulo. 


\section{Referencias}

Arias, S. (2011). La reforma constitucional de Derechos Humanos y la transversalización de los derechos. Revista IUS, 5(28), 68-84. http://www.scielo.org.mx/scielo.php?script=sci_ arttext\&pid=S1870-21472011000200004

Azcona, L. (1992). Isabel la Católica. Historia crítica de su vida y reinado. Biblioteca de Autores Cristianos.

Cano, G. L. (2012). Las primeras constituciones de Colombia, 1811-1821. Historia y Espacio, 8(39), 142-159.

Chaparro, J. (2010). Las relaciones político-militares en el marco de la transición política en Colombia 1810-1838. Silueta.

Comisión Colombiana de Juristas. (1997). Colombia, Derechos Humanos y Derecho Humanitario: 1996. Comisión Colombiana de Juristas.

Ibarra, M. (2019, junio 8). . Escuela de los Annales: origen, características y metodología. Consultado junio 28, 2020, en https://www.lifeder.com/escuela-annales/

Lassalle, F., \& Roces, W. (1994). ¿Qué es una Constitución? Panamericana.

Leiva, R. E. et al. (2018). Los derechos fundamentales de la Constitución Política de 1991 como resultado de un proceso constituyente deliberativo. Revista Derecho del Estado, 42, 149-180. https:// doi.org/10.18601/01229893.n42.06

Marchena, F. (1982). La institución militar en Cartagena de Indias 1700-1810. Escuela de Estudios Hispano-Americanos.

Marchena, F. (1990). The social world of the military in Peru and New Granada. The Colonial Oligarchies in conflict, 1750-1810. John Robert Fisher.

Martínez T. (2015). Brevísima relación de la destrucción de las Indias. / Bartolomé de las Casas (14841566). Editorial Universidad de Antioquia.

McFarlane, A. (2008). Los ejércitos coloniales y la crisis del Imperio Español, 1808-1810. Historia Mexicana, 58(229), 229-285.

Melo, G. (2017). Las reformas liberales de 1936 y 1968. https://www.banrepcultural.org/ biblioteca-virtual/credencial-historia/numero-13/las-reformas-liberales-de-1936-y-1968

Palomo, A. (2011). Apuntes teóricos para el estudio de la globalización desde la perspectiva de las relaciones internacionales. Confines de Relaciones Internacionales y Ciencia Política, 8(16), 69-109. http://www.scielo.org.mx/scielo.php?script=sci_arttext\&pid=S1870-35692012000200004

Pérez, A. (1959). 25 años de historia colombiana 1853-1878. Del centralismo a la federación. Editorial Sucre.

Pérez, K. (2005). Principio de igualdad: alcances y perspectivas. UNAM.

Piedrahíta, C. R. (1992). Las primeras constituciones políticas de Colombia y Venezuela. Ayer, 8, 75-146.

Pombo, M. A., \& Guerra, J. J. (1951). Constituciones de Colombia: recopiladas y precedidas de una breve reseña histórica. Ministerio de Educación Nacional.

Prado, L. (2017). Los avatares de la educación militar en la Nueva Granada (1820-1855). Historia y Memoria, 17, 317-343. https:/doi.org/10.19053/20275137.n17.2018.8282 
38 Perspectivas en Derechos Humanos y Derecho Internacional Humanitario para el Ejército Nacional de Colombia

Reglamento para las Milicias Disciplinadas de Infantería y Dragones del Nuevo Reyno de Granada, y Provincias agregadas a este Virreinato. (1794). Imprenta de la Viuda e Hijo de Marín.

Rubaii, N. M., Líppez-De Castro, S., \& Appe, S. (2019). Pueblos indígenas como víctimas de los genocidios pasados y actuales: un tema esencial para el currículo de administración pública en América Latina. Opera, 25, 29-54. https://doi.org/10.18601/16578651.n25.03

Sosa, G. (2006). Representación e Independencia 1810-1816. Instituto Colombiano de Historia y Antropología.

Tilly, C. (1992). Coerción capital y los Estados Europeos 990-1990. Alianza Editorial.

Título III de la Carta Magna de 1886. (s. f.). http://www.suin-juriscol.gov.co/viewDocument. asp?id=1826862

Tovar, H. (2017). La manumisión de esclavos en Colombia, 1809-1851. Aspectos sociales, económicos y políticos. Credencial Historia, 59. https://www.banrepcultural.org/biblioteca-virtual/ credencial-historia/numero-59/la-manumision-de-esclavos-en-colombia-1809-1851

Villa A. (1994). Derecho humanitario para Colombia. Defensoría del Pueblo. 